\title{
OPERATIVE TREATMENT OF PRESSURE SORES IN PARAPLEGICS BY ROTATION FLAP
}

\author{
By S. KRUPP, M.D., and G. A. ZÄCH, M.D. \\ Division of Plastic Surgery of the Surgical Department, Basle University, \\ Kantonsspital, and the Swiss Center for Paraplegics, Basle
}

\section{Introduction}

Between the opening of the Swiss Center for Paraplegics in Basle on I July 1967 and 30 April 1975, 4I paraplegics have been operated on by 65 flaps for pressure sores or unstable scars. Sixty out of 65 flaps were rotation or rotation-sliding flaps, five being bipedicle bridge flaps. The 65 flaps represent at most one-third of all pressure sores treated during this period of $7 \frac{3}{4}$ years. The locations of the lesions operated upon are shown in Table I; the complications are summarised and specified in Table II. None of these complications interfered with the final result.

Fresh pressure sores are always treated conservatively, independently of the extent and location of the lesion. The treatment starts with unburdening the lesion by getting the patient used to the prone position if necessary, debridement of necrotic tissue and application of moist dressings to clean the wound. When the wound contracture has come to an end, the patient has been carefully prepared, the suppurative drainage has stopped, and the bony prominences in the wound have been covered by granulation tissue, the patient is evaluated as to his or her suitability for operation (Krupp, I972; Meinecke, I974; Cotta et al., I975).

\section{TABLE I}

Location of lesion operated on by 65 flaps in 40 paraplegics

\begin{tabular}{|c|c|c|c|c|c|}
\hline \multirow[b]{2}{*}{ Location } & \multirow{2}{*}{$\begin{array}{l}\text { Number of } \\
\text { flaps }\end{array}$} & \multicolumn{2}{|c|}{ Rotation flaps } & \multicolumn{2}{|c|}{ Bipedicle bridge flaps } \\
\hline & & Pressure sores & Unstable scars & Pressure sores & Unstable scars \\
\hline Sacral & I6 & 5 & IO & - & I \\
\hline Ischial & $3 I$ & 6 & 25 & - & - \\
\hline Trochanteric & 18 & 6 & 8 & - & 4 \\
\hline & - & - & - & 一 & 一 \\
\hline Total & 65 & I7 & 43 & - & 5 \\
\hline
\end{tabular}

\section{TABLE II}

Twelve complications in 60 rotation flaps

$\begin{array}{ll}\text { Haemorrhages } & 8 \\ \text { Partial wound rupture } & 2 \\ \text { Partial flap necrosis } & \text { I } \\ \text { Infection } & \text { I }\end{array}$


(a)

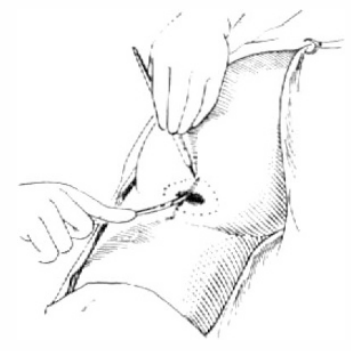

(c)
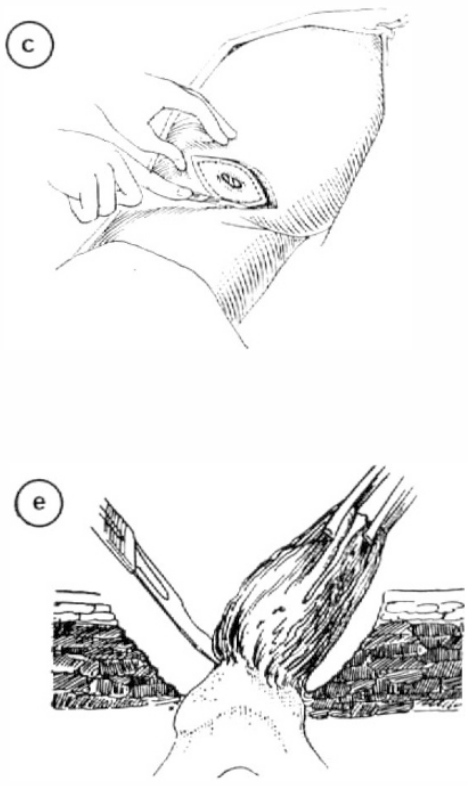

(b)

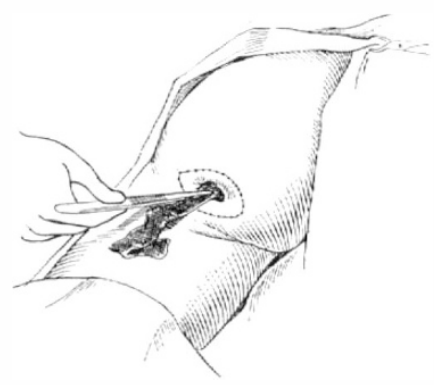

(d)

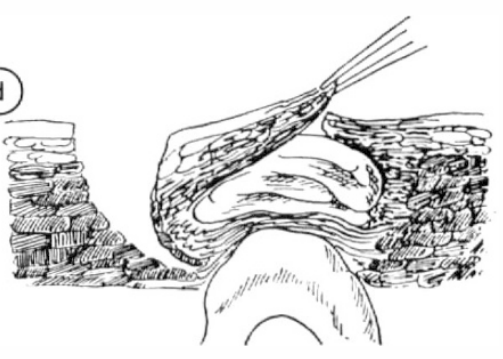

(f)

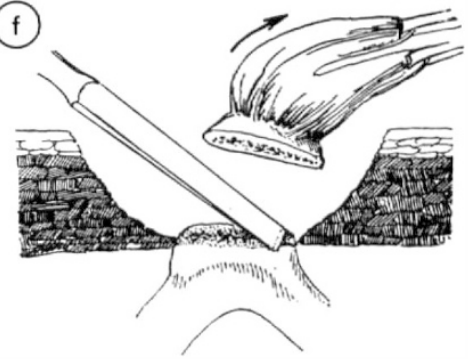

FIG. I

Excision of pressure sore and underlying bursa with its adjacent bone in the pseudotumour technique of Guttmann. (a) External size of the pressure sore, determining the extent of the undermining and marking the limits with ink. (b) Packing the ulcer cavity with stained strip gauze. $(c) \&(d)$ Excising the stained area en bloc down to the bone. $\quad(e) \&(f)$ Removing the affected portion of the underlying bony prominence.

The wound is excised by the pseudotumour technique of Guttmann (Guttmann, I956) (fig. I), and the rotation flap with its underlying fascia is mobilised. Bony prominences are resected and contoured subperiosteally (fig. 2), and any bony metaplasia in the adjacent soft tissue is removed. Finally the flap is placed in the defect and the wound closed in three layers. Four to six suction drains are placed; meticulous haemostasis during the operation has been achieved by suture 


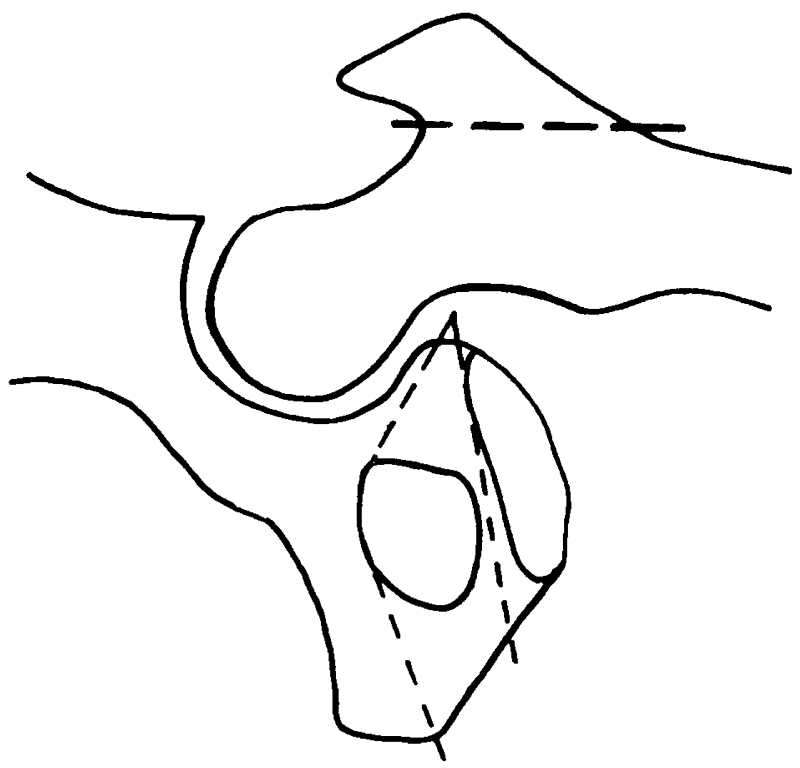

FIG. 2

Lines of limited resection of the ischial tuberosity, total ischiectomy and removal of trochanteric prominence.

ligation and cauterisation of small bleeding-points. Until definitive wound healing, i.e. for three weeks at least, the flap is free from load by either a supine or prone position of the patient (Krupp, I972).

The rotation flaps are always outlined generously in order to guarantee sufficient blood flow in the periphery of the flaps and closure of the wound with no tension at all. If necessary to overcome undue wound tension a split thickness skin graft is placed in the appropriate area. Large flaps have also the advantage that they may be used a second or even a third time by remobilisation if regression occurs (Campbell, i966).

To cover sacral pressure sores, the rotation flaps (fig. 3) as a rule are based caudally, so that the resultant scar will not be over weight-bearing areas (Campbell, I966; Zoltan, I97I). If necessary, because of technical reasons, we do not hesitate to base a flap cranially because we never have seen the resulting scar over the weight-bearing area interfere with function.

To cover lesions over the ischial bone, rotation-sliding flaps are based medially on the thigh (Fig. 4) (Campbell, 1966). The proximal ends of such flaps are usually de-epithelised in order to create a dermal fat flap, which fills the cavity and pads the bone. Therefore, we rarely rely on a biceps muscle flap to fill the cavity. If it is necessary to perform a total ischiectomy, pressure is shifted to the opposite side. That is why in such cases an ischiectomy is later carried out on the opposite side prophylactically.

Where there is only a caudal lesion with saddle anaesthesia, flaps may be rotated, as advocated by Guttmann, from the gluteal into the anaesthetic area and thereby prevents unrecognised pressure (Guttmann, I956).

In the trochanteric area, the flaps are based distally and laterally (Fig. 5) in order to preserve the medial aspect of the thigh for flaps which may be needed 

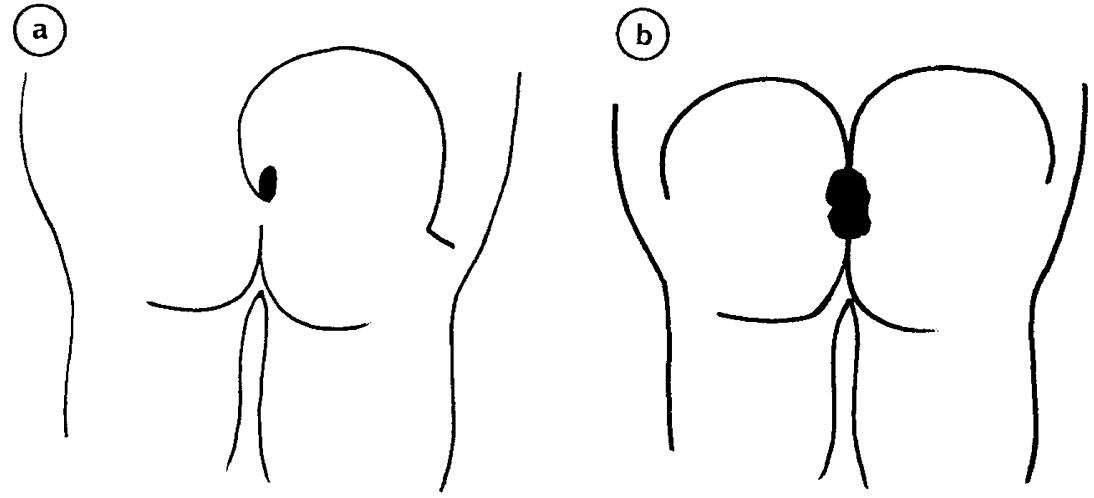

(c)
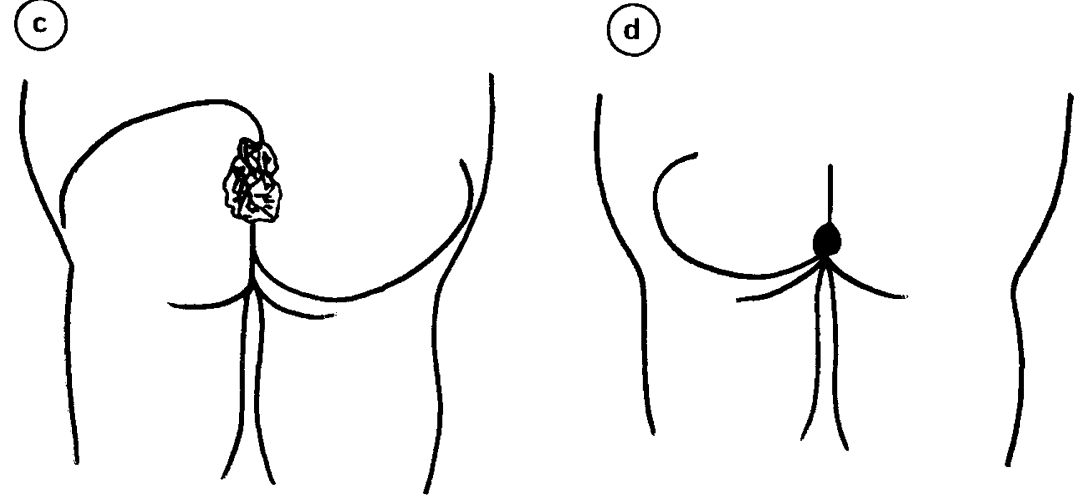

FIG. 3

Outline of rotation flaps in the sacral region: $(a)$ one inferiorly based rotation flap, $(b)$ two inferiorly based rotation flaps, $(c)$ one superiorly, one inferiorly based rotation flap, $(d)$ one superiorly based rotation flap.

for ischial lesions (Campbell, I966). In the trochanteric area, we often have to rely on a split thickness graft for wound closure to eliminate undue tension. The skin grafts are placed proximally in the wound and are well padded by muscles. They therefore never interfere with function.

\section{SUMMARY}

Sixty rotation flaps (in 40 paraplegics) to cover pressure sores and unstable scars in the region of the buttocks are reported. There were 12 complications (20 per cent), none jeopardising the result of the operation. Advantages of the rotation flap are its good blood supply if generously outlined and the possibility of using the same flap a second or even third time if necessary. 
(a)

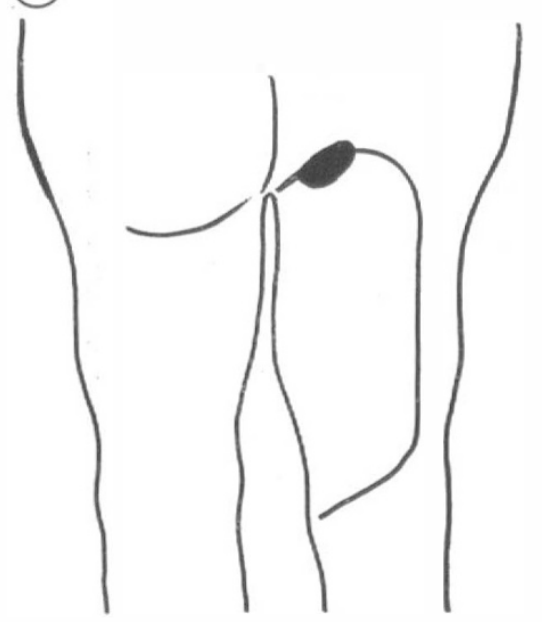

(c)

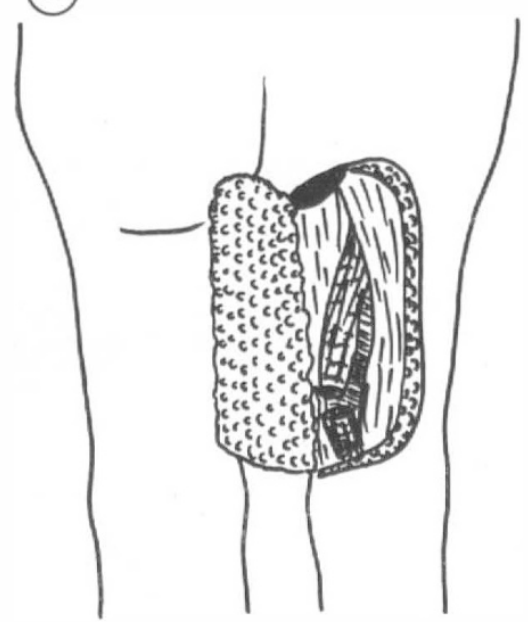

(b)

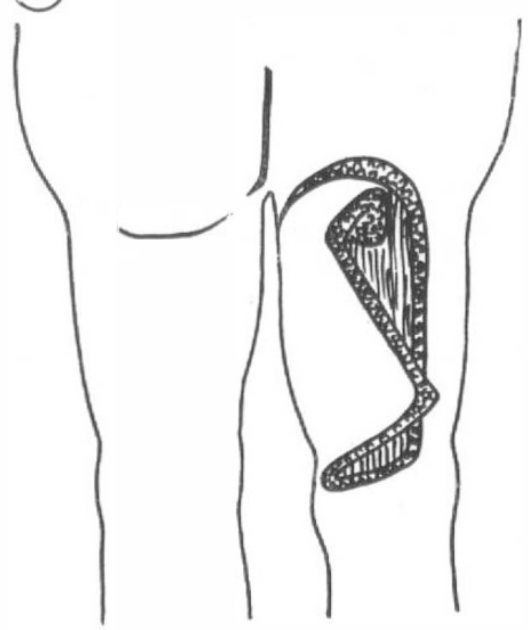

(d)

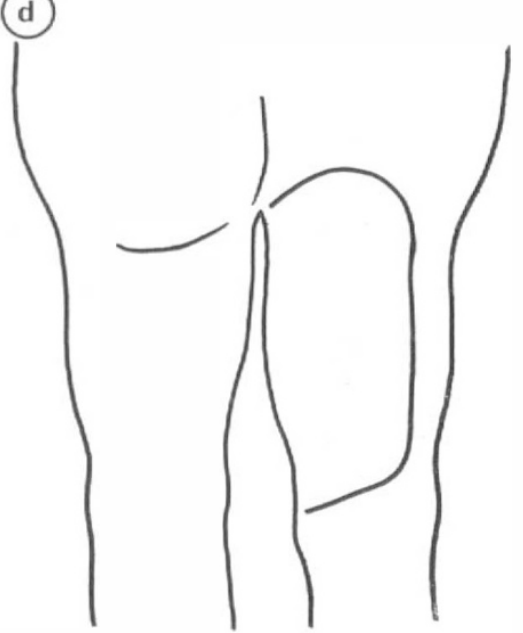

FIG. 4

(a) Outlining the medially based rotation flap and excising the ulcer and underlying prominence. (b) The superior part of the rotation-sliding flap is de-epithelised and fills the defect created by ulcer excision. (c) If necessary the biceps muscle is divided and rotated into the defect created by ulcer and bone resection. (d) Skin flap rotated into the defect and skin graft used to cover the donor area.

\section{RÉSUMÉ}

Pour couvrir des ulcères ou des cicatrices instables chez les paraplégiques, les auteurs se sont servis de lambeaux de rotation qui ont l'avantage d'avoir une bonne circulatiou s'ils sont dessinés généreusement.

Pour cette raison, ils peuvent être utilisés une deuxième fois en cas de récidive.

Pour 60 lambeaux, I2 complications ont été observées ( 20 pour cent) dont aucune n'a porté préjudice au résultat final. 


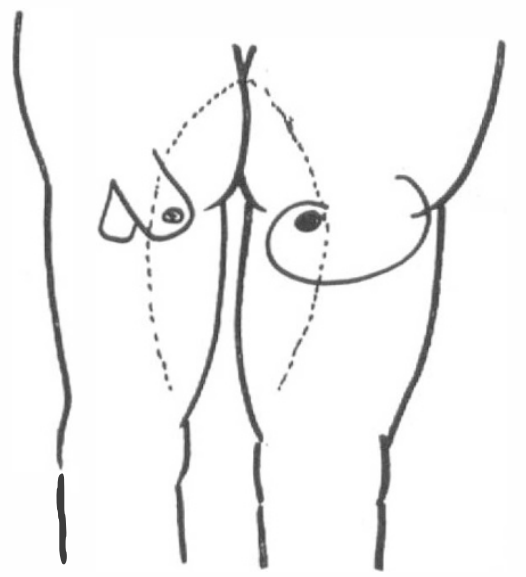

FIG. 5

Rotation and transposition flaps in saddle anaesthesia from sensitive gluteal area to cover pressure sores.
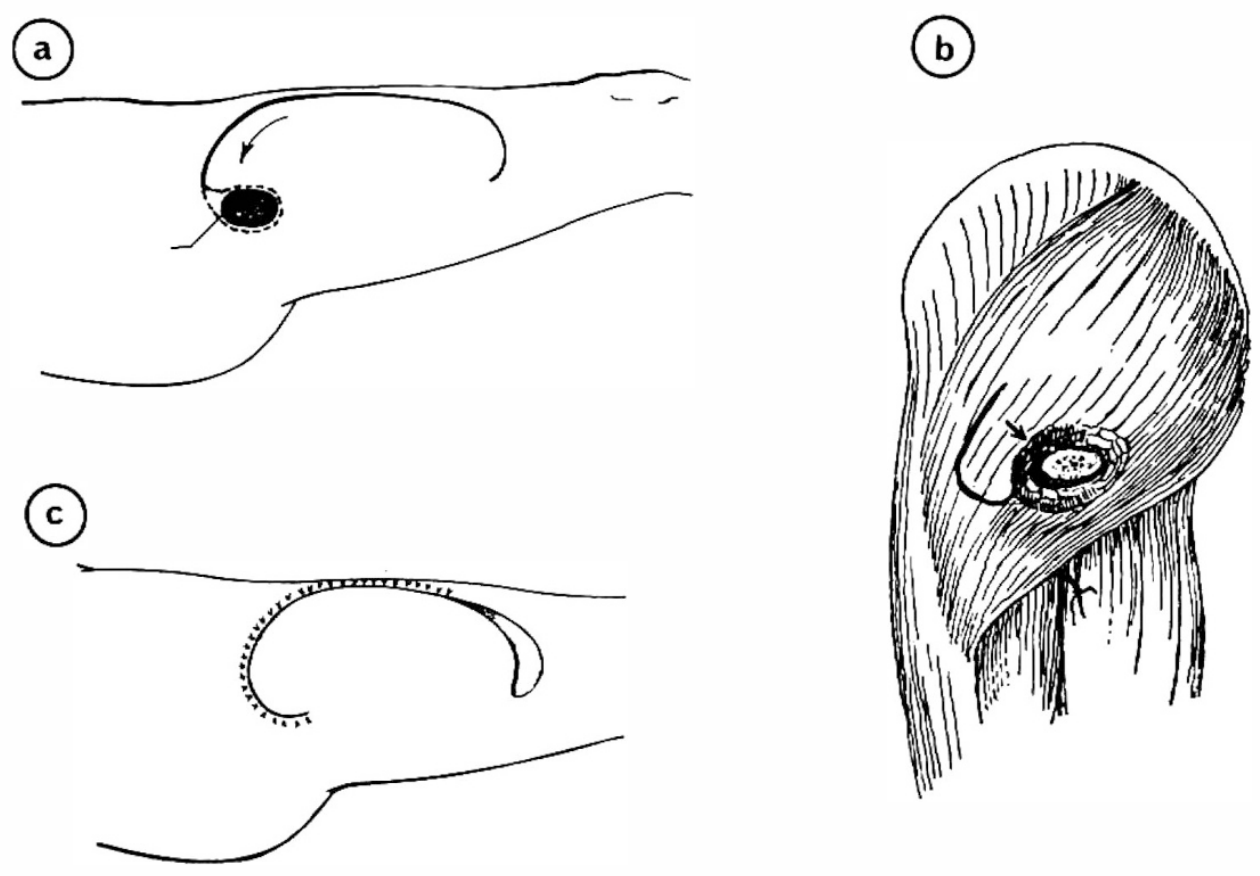

FIG. 6

(a) Outlining and mobilising a large, laterally based rotation flap and excising the pressure sore. (b) After having removed the trochanter, a local muscle flap is used to pad the skin flap. (c) Skin flap rotated into the defect and skin graft used to cover the donor area. 


\section{ZUSAMMENFASSUNG}

Es wird über 60 Rotationslappenplastiken bei 40 Paraplegikern zur Deckung von Druckulzera und unstabilen Narben berichtet. Es waren I2 Komplikationen (20 Prozent), vorwiegend Blutungen, zu verzeichnen, von denen keine das Endresultat beeinträchtigt hat.

\section{REFERENCES}

Cambrell, R. M. (1966). Treatment of the Pressure sore in Reconstructive Plastic Surgery, J. M. Converse (Ed.) Volume 5, I97I-I999. Philadelphia, London: W. B. Saunders.

Cotta, H., Remus, W. \& Plaue, R. (I975). Orthopädische Eingriffe bei Querschnittgelähmten. Orthopäde, 4, I I6-I 22.

GutTMANN, L. (1956). The problem of treatment of pressure sores in spinal paraplegics. Brit. F. Plast. Surg. 8.

KRUPP, S. (1972). The operative treatment of pressure sores in paraplegics. Wiederherstellungschir. u. Traum. 13, I59-182.

MeineCKE, F. W. (I974). Die Verletzungen der Wirbelsäule mit Markschäden. In Chirurgie der Gegenwart, Bd. 4, pp. I-5I, Herausgeber: R. Zenker, F. Drucker, W. Schink. Littau, Schwarzenberg, München, Berlin, Wien.

Zoltan, J. (1974). Lappenplastiken im Stammbereich. Die Behandlung des Dekubitus. Bd. 2, Beitrag 46, pp. I09-I 2 I, Handbuch der plastischen Chirurgie. Hrsg: E. Gohbrandt, J. Gabka, A. Berndorfer. Walter de Gruyter, Berlin, New York.

\section{Discussion}

Dr Nuseibeh (G.B.) demonstrated slides of rotation flaps in paraplegics at Stoke Mandeville. Any paraplegic runs the risk of forming pressure sores more than once and multiple pressure sores at the same time. This trochanteric sore has been treated with circular incision and by direct sutures. If this fails, I am in trouble, I cannot treat him again. This is my objection to flap treatment in pressure sores.

Sir Ludwig GuttmanN (G.B.). May I ask Dr Krupp when you excise the greater trochanter do you get spontaneous fractures easily.

DR KRUPP (Switzerland). We have had no spontaneous fractures, we have sometimes feared this but we have never actually had them.

DR A. G. HARDY (G.B.). I think that one of the great risks of taking the greater trochanter off is that you may get involvement of the hip joint. The capsule of the hip extends down to the inside of the greater trochanter and we have had in years gone by infective arthritis after doing a plastic manoeuvre in removing the greater trochanters. Just a word of warning, this has happened to me three or four times, and I am sure it was associated with opening the hip joint.

DR KRUPP (Switzerland). I agree with you that there is the same risk but I think if you operate very carefully you can avoid it.

DR F. W. MEINECKE (Germany). We also removed the trochanter for years when I was in Bochum, and I didn't see any infection. But I entirely agree with Dr Hardy, it may be very difficult to discover the capsule of the hip joint and the scar tissue and because of that you must be very careful, and probably it is better not to remove the bone.

Dr A. Key (S. Africa). I would like to agree with the previous speaker and Dr Krupp, who gave the paper, that rotation flaps are the best. I would like to ask one question-I notice that the flaps are taken at Basle from very low down involving the area of the caliper. Have you not had any trouble with your calipers?

DR KRUPP. None.

ProfESSOR M. Weiss (Poland). I want to ask the gentleman from Stoke Mandeville what to do if the rotation flap is not indicated.

DR NusEIBEH (G.B.). We have been treating pressure sores for a long time and the method which we follow is the Sir Ludwig Guttmann pseudo-tumour technique. 